\title{
Expression and prognostic significance of contactin I in human hepatocellular carcinoma
}

This article was published in the following Dove Press journal:

OncoTargets and Therapy

19 January 2016

Number of times this article has been viewed

\author{
Guang-Yao Li ${ }^{1,2, *}$ \\ Mei Huang $1,2, *$ \\ Ting-Ting $\operatorname{Pan}^{1,2}$ \\ Wei-Dong Jia ${ }^{1,2}$ \\ 'Department of General Surgery, \\ Affiliated Provincial Hospital, \\ Anhui Medical University, ${ }^{2}$ Anhui \\ Province Key Laboratory of \\ Hepatopancreatobiliary Surgery, Hefei, \\ People's Republic of China \\ *These authors contributed equally \\ to this work
}

\begin{abstract}
Background: CNTN1, a member of the CNTN family of neural cell-recognition molecules, is involved in tumor invasion and metastasis. Although the expression of CNTN1 has been reported in several human malignancies, the expression of CNTN1 in hepatocellular carcinoma (HCC) and its correlation with prognosis remain unclear. The aim of this study was to evaluate the expression of CNTN1 and determine the clinicopathological parameters and prognostic value of CNTN1 in HCC patients.
\end{abstract}

Materials and methods: Quantitative real-time polymerase chain-reaction and Western blotting assays were performed to assess messenger RNA and protein levels of CNTN1 in 20 matched HCC specimens. The clinical and prognostic significance of CNTN1 in 90 cases of HCC was determined by immunohistochemistry.

Results: CNTN1 expression was higher in HCC compared to the expression found in adjacent tissues at both messenger RNA and protein levels $(P<0.01)$. Notably, immunohistochemical results revealed that CNTN1 expression was significantly higher in HCC compared to adjacent tissues ( $54.4 \%$ vs $12.2 \%, P=0.01$ ). Furthermore, positive CNTN1 expression was associated with tumor size, tumor capsulae, status of metastasis, and tumor-node-metastasis stage. KaplanMeier survival analysis showed that high CNTN1 was correlated with reduced overall survival (OS) rate $(P<0.001)$ and disease-free survival (DFS) rate $(P=0.001)$. Multivariate analysis identified CNTN1 as an independent poor prognostic factor of OS and DFS in HCC patients ( $P=0.007$ and $P=0.002$, respectively).

Conclusion: Our results suggest that CNTN1 could play an important role in HCC and serve as an independent unfavorable prognostic factor for OS and DFS and a potential therapeutic target for HCC.

Keywords: CNTN1, hepatocellular carcinoma, expression, prognosis, immunohistochemistry

\section{Introduction}

Hepatocellular carcinoma (HCC), a predominant histological subtype of primary liver cancer, is the fifth most commonly diagnosed cancer worldwide and the second most common cause of cancer-related mortality in men. Moreover, it is the seventh most common cancer and the sixth most lethal in women. ${ }^{1}$ Despite improvements in the diagnosis and treatment of $\mathrm{HCC}$, its prognosis is gloomy, with a 5 -year survival of $11 \%{ }^{2}$ One of the most important reasons for this low survival rate is that the majority of HCC patients are diagnosed at an advanced stage, where curative treatments are not effective or feasible due to tumor spread. Therefore, the identification of specific biomarkers, especially for early stage tumors, is important for improving HCC prognosis.

The glycosyl-phosphatidylinositol anchor neural cell-adhesion molecule CNTN1 is a member of the immunoglobulin superfamily, which consists of N-CAM, L1, and Nr-CAM. CNTN1 mediates cell-surface interaction in the nervous system, and is
Correspondence: Wei-Dong Jia

Department of General Surgery, Affiliated Provincial Hospital, Anhui Medical University, 17 Lujiang Road, Luyang, Hefei, Anhui 23000I, People's Republic of China

Tel/fax +8655I 62283740

Email jwd2003@I63.com 
involved in certain signal-transduction pathways, such as being a functional ligand for Notch. ${ }^{3}$ However, previous studies have reported CNTN1 to be upregulated in a few types of cancer, such as lung cancer, ${ }^{4}$ squamous cancer, ${ }^{5,6}$ and gastric cancer, ${ }^{7,8}$ suggesting that CNTN1 could have a role in cancer progression, invasion, and metastasis. Mounting evidence suggests that other members of this immunoglobulin superfamily facilitate motility, invasion, and metastasis in cancer. ${ }^{9,10}$ Although many studies have investigated the upregulation of CNTN1 in different types of human cancer, the significance of aberrant expression of CNTN1 in HCC has not been determined.

In the present study, we detected the expression of CNTN1 in HCC and in surrounding nontumor tissue by quantitative real-time polymerase chain reaction (qRT-PCR) and Western blotting. Additionally, we performed immunohistochemical staining of CNTN1 in tumor tissues from 90 patients with $\mathrm{HCC}$ and we evaluated the association between the level of CNTN1 expression and clinicopathological parameters, as well as postoperative survival.

\section{Materials and methods Patients and tissue samples}

Tumor tissues and surrounding nontumor tissues $(2 \mathrm{~cm}$ from the tumor edge) were obtained from 90 patients with HCC who had undergone curative hepatectomy from 2006 to 2010 at the Affiliated Provincial Hospital of Anhui Medical University, Hefei, People's Republic of China (PRC). In addition, snap-frozen tumor and paracarcinomatous tissues were obtained from 20 patients for analysis by qRT-PCR and Western blotting. Pathologists confirmed the diagnoses of these HCC samples. None of the patients accepted any anticancer therapy before surgery. Demographic and clinicopathological data, such as age, sex, tumor size, number of tumor nodules, tumor capsulae, vascular invasion, Edmondson grade, hepatitis B surface-antigen status, cirrhosis, Child-Pugh grade, levels of preoperative AFP, and tumor-node-metastasis (TMN) stage, were retrieved from medical records and are presented in Table 1.

These patients included 73 males and 17 females with a mean age of 54 (range 19-74) years. Tumor differentiation and pathological tumor stage were defined by the Edmondson grading system and the tumor-node-metastasis (TNM) classification of the International Union Against Cancer, respectively. ${ }^{11}$ Liver function was estimated using the ChildPugh classification. Follow-up data were collected from all 90 patients, and the mean follow-up period in the present investigation was 25.1 (range 2-66) months. Overall survival
Table I CNTNI expression in relation to clinicopathologic features

\begin{tabular}{|c|c|c|c|c|}
\hline \multirow[t]{2}{*}{ Parameters } & \multirow[t]{2}{*}{ Total } & \multicolumn{2}{|l|}{ CNTNI } & \multirow[t]{2}{*}{$P$-value } \\
\hline & & Negative & Positive & \\
\hline \multicolumn{4}{|l|}{ Age, years } & \multirow[t]{3}{*}{0.277} \\
\hline$\leq 60$ & 56 & 28 & 28 & \\
\hline$>60$ & 34 & 13 & 21 & \\
\hline \multicolumn{4}{|l|}{ Sex } & \multirow[t]{3}{*}{0.346} \\
\hline Male & 73 & 35 & 38 & \\
\hline Female & 17 & 6 & II & \\
\hline \multicolumn{4}{|c|}{ Tumor capsulae } & \multirow[t]{3}{*}{$<0.001$} \\
\hline Absent & 47 & 12 & 35 & \\
\hline Present & 43 & 29 & 14 & \\
\hline \multicolumn{4}{|c|}{ Tumor size $(\mathrm{cm})$} & \multirow[t]{3}{*}{0.004} \\
\hline$\leq 5$ & 28 & 19 & 9 & \\
\hline$>5$ & 62 & 22 & 40 & \\
\hline \multicolumn{4}{|c|}{ Vascular invasion } & \multirow[t]{3}{*}{0.319} \\
\hline No & 68 & 33 & 35 & \\
\hline Yes & 22 & 8 & 14 & \\
\hline \multicolumn{4}{|c|}{ Edmondson grade } & \multirow[t]{3}{*}{0.686} \\
\hline I-II & 44 & 21 & 23 & \\
\hline III-IV & 46 & 20 & 26 & \\
\hline \multicolumn{4}{|c|}{ Status of metastasis } & \multirow[t]{3}{*}{0.001} \\
\hline Absent & 64 & 36 & 28 & \\
\hline Present & 26 & 5 & 21 & \\
\hline \multicolumn{4}{|l|}{$\operatorname{AFP}(\mathrm{ng} / \mathrm{mL})$} & \multirow[t]{3}{*}{0.207} \\
\hline$\leq 20$ & 29 & 16 & 13 & \\
\hline$>20$ & 61 & 25 & 36 & \\
\hline \multicolumn{4}{|l|}{$\mathrm{HBsAg}$} & \multirow[t]{3}{*}{0.165} \\
\hline Negative & 14 & 4 & 10 & \\
\hline Positive & 76 & 37 & 39 & \\
\hline \multicolumn{4}{|l|}{ Cirrhosis } & \multirow[t]{3}{*}{0.873} \\
\hline Absent & 16 & 7 & 9 & \\
\hline Present & 74 & 34 & 40 & \\
\hline \multicolumn{4}{|c|}{ Child-Pugh grade } & \multirow[t]{3}{*}{0.141} \\
\hline$A$ & 84 & 40 & 44 & \\
\hline B & 6 & 1 & 5 & \\
\hline \multicolumn{4}{|l|}{ TNM stage } & \multirow[t]{3}{*}{0.009} \\
\hline I-II & 48 & 28 & 20 & \\
\hline III-IV & 42 & 13 & 29 & \\
\hline
\end{tabular}

Abbreviations: $\mathrm{HBsAg}$, hepatitis $B$ surface antigen; TNM, tumor, node, metastasis; AFP, alpha fetoprotein.

(OS) time was calculated from the date of surgery to the date of death or last observation. Disease-free survival (DFS) time was defined as the interval between the date of operation and the date of first verified recurrence. If recurrence was not diagnosed, the survivors were censored on the date of death or the last date of follow-up. Informed consent was obtained from each patient, and the study protocol was approved by the Research Ethics Committee of Anhui Provincial Hospital, as stipulated by the Declaration of Helsinki.

\section{Quantitative real-time PCR}

Total RNA obtained from snap-frozen samples was extracted by using Trizol according to the manufacturer's protocol. 
Complementary DNA was synthesized from $2 \mu \mathrm{g}$ of total RNA using the RevertAid First Strand complementary DNA-synthesis kit (Thermo Fisher Scientific, Waltham, MA, USA). The gene-specific primers for CNTN1 were designed as follows: forward, 5'-TTGGGAAGATGGTAGCTTGG-3'; reverse, 5'-TAGTAACAAGGGTTCCAGTGC-3'. For standardization of RNA quality control, expression of GAPDH in each sample was quantified by using the primer set 5'-CCTAGTTCGTCATGGGTGTGAACCA-3' (forward) and 5'-GCCAGTAGAGGCAGGGATGATGTTC-3' (reverse). Messenger RNA (mRNA) expression of CNTN1 was determined using SYBR green-based RT-PCR performed on a PikoReal RT-PCR system (Thermo Fisher Scientific) with the following conditions: an initial denaturation step of $95^{\circ} \mathrm{C}$ for 5 minutes, followed by 40 amplification cycles involving denaturation at $95^{\circ} \mathrm{C}$ for 10 seconds, annealing at $60^{\circ} \mathrm{C}$ for 30 seconds, and elongation at $72^{\circ} \mathrm{C}$ for 30 seconds. A melting-curve analysis was performed to monitor PCR-product purity, and relative gene-expression data were analyzed using the $2^{-\Delta \Delta \mathrm{Ct}}$ method.

\section{Western blot}

Snap-frozen tumor and corresponding paracarcinomatous tissues were lysed with radioimmunoprecipitation-assay lysis buffer (Beyotime Institute of Biotechnology, Shanghai, PRC), and protein concentration was subsequently estimated by the bicinchoninic acid protein assay. Then, equal amounts of protein samples were separated on $10 \%$ sodium dodecyl sulfate polyacrylamide gel electrophoresis gels and transferred onto polyvinylidene difluoride membranes (EMD Millipore, Billerica, MA, USA). After being blocked with $5 \%$ nonfat milk, membranes were incubated overnight at $4{ }^{\circ} \mathrm{C}$ with rabbit primary antibodies against human CNTN1 (Abcam PLC, Cambridge, UK) and human GAPDH (Zhongshan Golden Bridge Biotechnology Co Ltd, Beijing, PRC). After being washed with Tris-buffered saline/0.1\% Tween three times, membranes were incubated with secondary antibodies for 2 hours at room temperature. The specific protein bands were captured and visualized using an AlphaEaseFC imaging system (Alpha Innotech, San Leandro, CA, USA). The integrated density value (IDV) of each band was detected by drawing a rectangle outlining the band using the AlphaEaseFC software with auto-background subtraction. A total IDV by summation of each band IDV was used when a protein had double bands. The expression levels of CNTN1 proteins were quantified by normalization of the IDVs of those protein bands to that of actin bands on the same blot. GAPDH was used as an internal control.

\section{Immunohistochemistry}

Serial tissue sections ( $4 \mu \mathrm{m}$ thick) were deparaffinized with xylene, rehydrated, and subjected to microwave antigen retrieval in citrate buffer ( $\mathrm{pH} \mathrm{6.0)} \mathrm{for} 20$ minutes. Endogenous peroxidase activity was quenched by $3 \%$ hydrogen peroxide for 10 minutes. Afterward, the sections were incubated at $4{ }^{\circ} \mathrm{C}$ overnight with monoclonal antibody (anti-CNTN1; Abcam) in a humidified chamber. After being washed, the sections were incubated for 30 minutes with horseradish peroxidase-conjugated secondary antibody (Zhongshan Golden Bridge Biotechnology). Immunoreactivity was visualized with chromogen 3,3'-diaminobenzidine. Finally, all slides were counterstained with hematoxylin, dehydrated, and mounted. Under the same conditions, phosphate-buffered saline served as the negative control for the primary antibody, and a known immunopositive slide was used as the positive control. Tumor expression of CNTN1 was semiquantitatively evaluated using a previously reported method, ${ }^{12}$ and the percentage of staining-cell scores ( 0 , no staining; 1 point, $<10 \%$; 2 points, $10 \%-30 \%$; 3 points, $>30 \%)$ and the staining-intensity scores ( 0 point, negative; 1 point, weak intensity; 2 points, moderate intensity; 3 points, strong intensity) were summed. Sum scores with $\geq 3$ points were considered positive, while sum scores with $<3$ points served as negative. All sections were assessed by two pathologists who were blinded to clinical data.

\section{Statistical analysis}

All statistical analyses were carried out using SPSS 17.0 software (SPSS Inc, Chicago, IL, USA). Continuous data are presented using mean \pm standard deviation. Differences in CNTN1 mRNA and protein levels among tissue samples were examined by the independent Student $t$-test. The $\chi^{2}$-test was performed to analyze categorical variables. Survival analysis was determined by the Kaplan-Meier method, while differences between survival rates were evaluated using the log-rank test. Prognostic factors that were significant in univariate analyses were included in multivariate analyses, which were carried out by the Cox proportional-hazard model. $P$-values $<0.05$ were regarded as statistically significant.

\section{Results Expression of CNTNI mRNA in HCC tissues}

The mRNA level of CNTN1 was detected for 20 paired tumor and adjacent nontumor samples by qRT-PCR. The mean expression levels of CNTN1 mRNA are shown in Figure 1. It was found that the median CNTN1 mRNA expression 


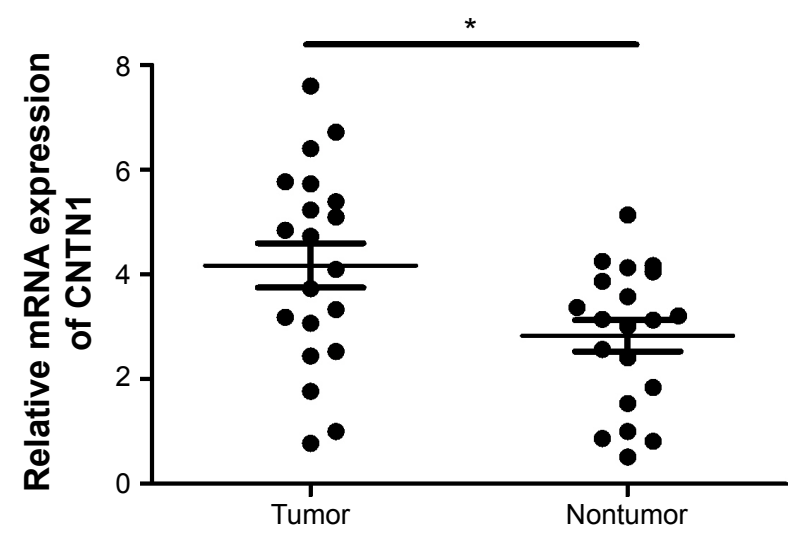

Figure I Real-time PCR analysis of CNTNI expression in 20 pairs of HCCs and adjacent nontumorous tissues.

Note: $* P<0.05$.

Abbreviations: PCR, polymerase chain reaction; HCC, hepatocellular carcinoma; mRNA, messenger RNA.

was significantly increased in HCC tumor tissues compared with adjacent nontumor tissues $(4.17 \pm 1.90$ vs $2.83 \pm 1.34$, $P<0.05$ ), and $70 \%$ of subjects ( 14 of 20 ) were found to have higher CNTN1 mRNA expression in tumor tissues.

\section{Expression of CNTNI protein in HCC tissue samples}

CNTN1 was detected in all $20 \mathrm{HCC}$ tumors and corresponding paracarcinomatous samples to determine its expression at the protein level using Western blotting. As shown in Figure 2, CNTN1 protein levels in HCC tissues and matched adjacent nontumor tissues were $1.32 \pm 0.61$ and $0.83 \pm 0.50$, respectively $(P<0.05)$. This result (13 of 20) was consistent with the qRT-PCR of the tumor samples $(P<0.05)$.

\section{CNTNI expression in HCC and its relationship with clinicopathological parameters}

The expression of CNTN1 in 90 HCC samples and the matched corresponding paracarcinomatous specimens was determined using immunohistochemical analysis, which showed that CNTN1 staining was mainly located in the cytoplasm of tumor cells with varying staining intensity (Figure 3). Additionally, CNTN1 expression was detected in $54.4 \%$ (49/90) of HCC tumor tissues, which was significantly higher than the $12.2 \%$ (11/90) found for adjacent nontumor tissues. Associations between tissue CNTN1 expression and clinicopathological parameters in HCC were analyzed, and the expression level of CNTN1 was significantly correlated with tumor capsulae $(P<0.001)$, larger tumor size $(P=0.004)$, status of metastasis $(P=0.001)$, and TNM stage $(P=0.009)$. However, CNTN1 immunoreactivity showed no significant correlation
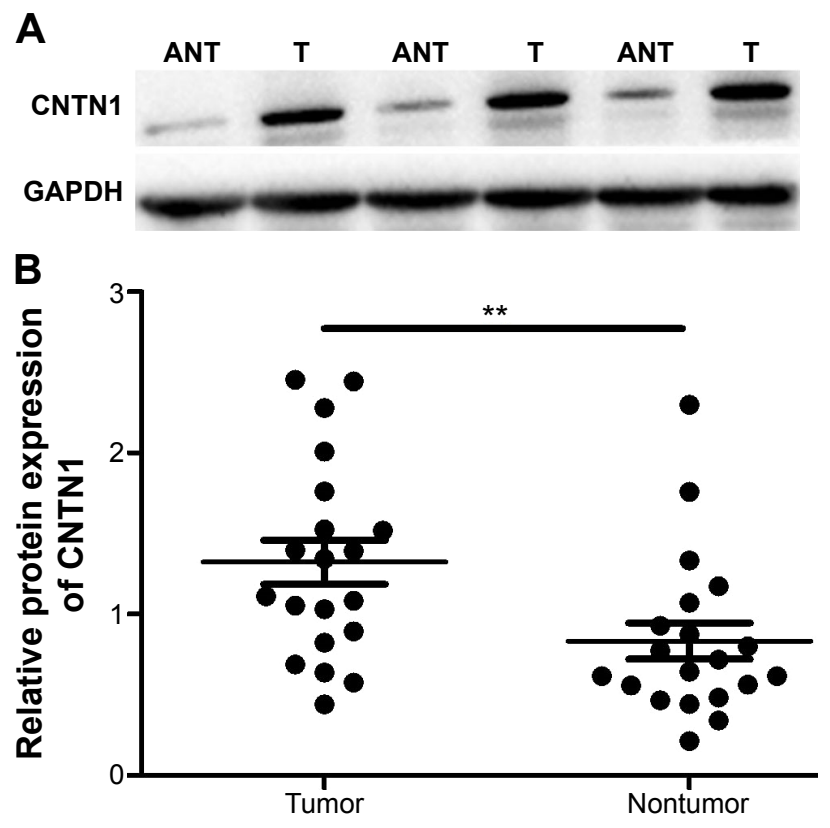

Figure 2 Western blotting analysis of CNTNI expression in tissues from HCC tumorous and adjacent nontumorous tissues.

Notes: (A) Representative results of CNTNI-protein expression in paired HCC tumorous tissues (T) and the matched adjacent nontumorous tissues (ANT) from three patients. CNTNI-protein expression was normalized to GAPDH. (B) All of the paired HCC tissues and the matched adjacent noncancerous tissues from 20 patients. $* * P<0.01$.

Abbreviation: $\mathrm{HCC}$, hepatocellular carcinoma.

with other parameters, such as age, sex, Edmondson grade, vascular invasion, serum AFP, hepatitis B surface-antigen status, cirrhosis, or Child-Pugh grade (Table 1).

\section{Relationship between CNTNI expression and prognosis}

Kaplan-Meier curve (Figure 4) analysis was used to assess the relationship between CNTN1 expression and patient survival. The log-rank test revealed that the OS time of HCC patients whose tumor tissue scored positively for CNTN1 expression (19.96 \pm 9.39 months) was markedly shorter than for those who scored negatively for CNTN1 expression (31.27 \pm 11.45 months, $P<0.001$; Figure 4A). Likewise, patients with $\mathrm{CNTN} 1^{+}$expression (13.61 \pm 8.63 months) had a shorter DFS time when compared with $\mathrm{CNTN1}^{-}$patients (24.51 \pm 10.41 months, $P<0.001$; Figure 4B). Univariate analysis of prognostic factors showed that CNTN1 expression, tumor size, tumor capsulae, serum AFP, vascular invasion, status of metastasis, Edmondson grade, and TNM stage had significant prognostic influences on OS and DFS (Table 2). Moreover, multivariate survival analysis revealed CNTN1 expression as an independent prognostic factor for OS (hazard ratio $2.383,95 \%$ confidence interval 1.262-4.503; $P=0.007$ ) and DFS (hazard ratio 2.356; $95 \%$ 

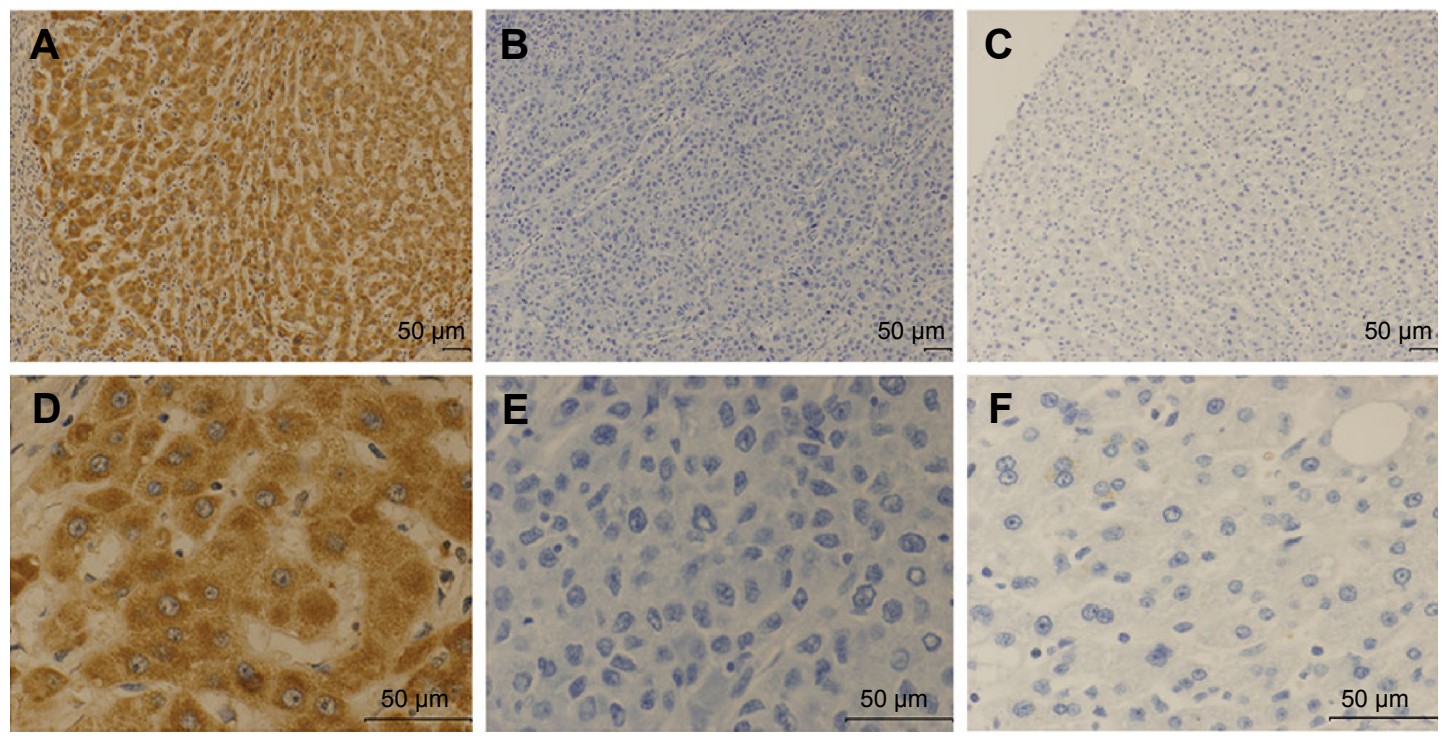

Figure 3 Representative immunohistochemical staining of CNTNI in HCC and adjacent noncancerous liver tissues.

Notes: (A, D) High expression of CNTNI in HCC tissue cells. (B, E) Negative expression of CNTNI in HCC tissue cells. (C, F) Negative expression of CNTNI in adjacent noncancerous tissue cells. (A-C) Magnification I00x; (D-F) magnification 400x.

Abbreviation: HCC, hepatocellular carcinoma.

confidence interval $1.370-4.049 ; P=0.002)$, along with tumor size, tumor capsulae, serum AFP, vascular invasion, status of metastasis, and TNM stage $(P<0.05$, Table 3$)$.

\section{Discussion}

CNTN1 belongs to the contactin subgroup of the immunoglobulin superfamily, which also includes CNTN2, -5 , and -6.
The expression and function of CNTN1 has been generally characterized in the central nervous system, and is involved in the regulation of neurite growth, synapse formation, fasciculation, and myelin organization. ${ }^{13-15}$ Additionally, mutations in the CNTN1 gene can cause a familial type of lethal congenital myopathy. ${ }^{16}$ Increasing numbers of studies have demonstrated that CNTN1 is altered in several cancers,
A

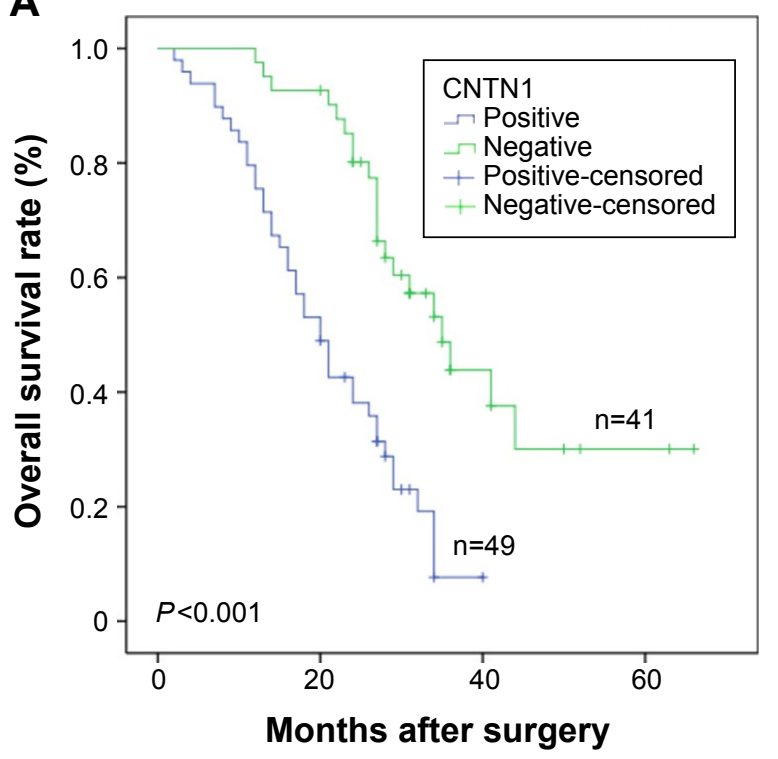

B

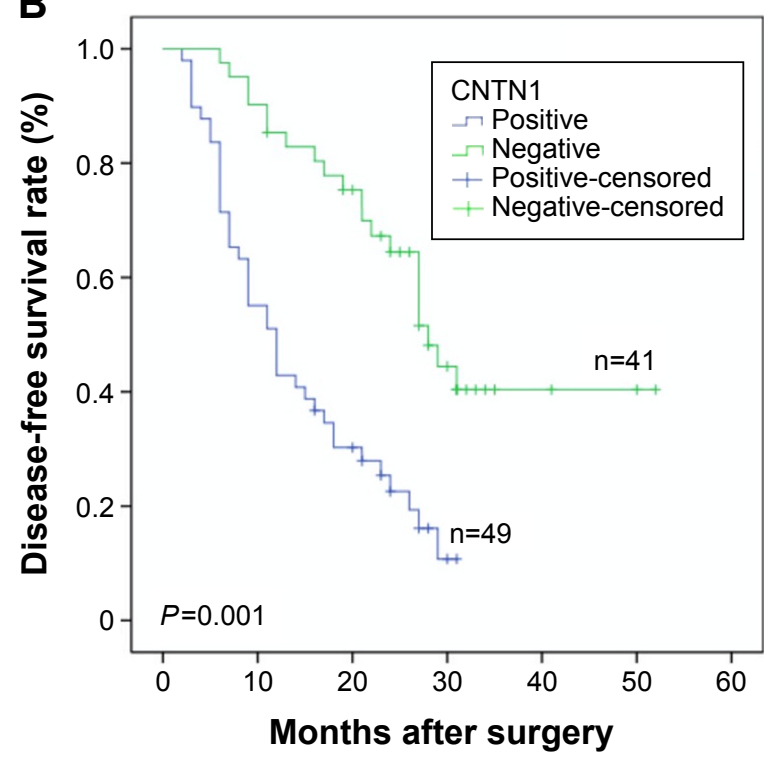

Figure 4 Kaplan-Meier analysis of OS and DFS curves of patients with HCC based on CNTNI expression as positive or negative.

Notes: (A) OS curve of patients with HCC based on CNTNI expression; (B) DFS curve of patients with HCC based on CNTNI expression. HCC patients with CNTNI+ showed notably worse OS and DFS rates than those with CNTNI-.

Abbreviations: OS, overall survival; DFS, disease-free survival; HCC, hepatocellular carcinoma. 
Table 2 Univariate analysis of factors associated with OS and DFS

\begin{tabular}{|c|c|c|c|c|}
\hline \multirow[t]{2}{*}{ Parameters } & \multicolumn{2}{|l|}{ OS } & \multicolumn{2}{|l|}{ DFS } \\
\hline & $95 \% \mathrm{Cl}$ & $P$-value & $95 \% \mathrm{Cl}$ & $P$-value \\
\hline \multicolumn{5}{|l|}{ CNTNI } \\
\hline Negative & $33.77 \mid-47.433$ & $<0.001$ & $24.087-33.736$ & $<0.001$ \\
\hline Positive & |8.085-24.086 & & II.432-16.54| & \\
\hline \multicolumn{5}{|l|}{ Age, years } \\
\hline$\leq 60$ & $24.308-35.319$ & 0.578 & $17.680-26.149$ & 0.765 \\
\hline$>60$ & $25.425-39.275$ & & $15.483-25.775$ & \\
\hline \multicolumn{5}{|l|}{ Sex } \\
\hline Male & $24.935-34.332$ & 0.508 & $18.210-25.478$ & 0.659 \\
\hline Female & $23.151-45.624$ & & $\mid 1.457-26.713$ & \\
\hline \multicolumn{5}{|c|}{ Tumor capsulae } \\
\hline Absent & $17.816-26.069$ & $<0.001$ & $10.468-15.426$ & $<0.001$ \\
\hline Present & $33.834-48.569$ & & $26.244-36.688$ & \\
\hline \multicolumn{5}{|c|}{ Tumor size $(\mathrm{cm})$} \\
\hline$\leq 5$ & $37.154-53.817$ & $<0.001$ & $23.267-34.276$ & 0.006 \\
\hline$>5$ & $20.478-28.00 I$ & & $13.816-19.166$ & \\
\hline \multicolumn{5}{|c|}{ Vascular invasion } \\
\hline No & $29.434-39.970$ & $<0.00$ I & $20.646-28.429$ & $<0.001$ \\
\hline Yes & |3.433-2|.567 & & $8.031-14.515$ & \\
\hline \multicolumn{5}{|c|}{ Edmondson grade } \\
\hline I-II & $31.625-46.169$ & $<0.00$ I & $22.113-32.808$ & 0.001 \\
\hline III-IV & $|9.53|-28.778$ & & $12.525-19.072$ & \\
\hline \multicolumn{5}{|c|}{ Status of metastasis } \\
\hline Absent & $30.672-41.868$ & $<0.001$ & $21.169-29.392$ & $<0.001$ \\
\hline Present & $|3.942-20.73|$ & & $8.882-|4.87|$ & \\
\hline \multicolumn{5}{|l|}{$\operatorname{AFP}(\mathrm{ng} / \mathrm{mL})$} \\
\hline$\leq 20$ & $33.426-49.973$ & $<0.001$ & $21.912-34.053$ & 0.002 \\
\hline$>20$ & $20.345-26.234$ & & 14.455-20.338 & \\
\hline \multicolumn{5}{|l|}{$\mathrm{HBsAg}$} \\
\hline Negative & $19.319-30.025$ & 0.827 & 13.355-24.645 & 0.983 \\
\hline Positive & $26.183-35.923$ & & 17.664-24.73 & \\
\hline \multicolumn{5}{|l|}{ Cirrhosis } \\
\hline Absent & $25.142-46.629$ & 0.32 & |3.98|-29.894 & 0.927 \\
\hline Present & $23.835-32.732$ & & $16.980-22.553$ & \\
\hline \multicolumn{5}{|c|}{ Child-Pugh grade } \\
\hline$A$ & $26.526-30.052$ & 0.224 & $18.078-25.063$ & 0.559 \\
\hline B & $18.915-29.974$ & & 12.357-22.976 & \\
\hline \multicolumn{5}{|l|}{ TNM stage } \\
\hline I-II & $33.516-47.116$ & $<0.001$ & $25.262-35.076$ & $<0.001$ \\
\hline III-IV & $16.993-23.518$ & & $9.632-14.320$ & \\
\hline
\end{tabular}

Abbreviations: OS, overall survival; DFS, disease-free survival; $\mathrm{Cl}$, confidence interval; $\mathrm{HBsAg}$, hepatitis B surface antigen; TNM, tumor, node, metastasis; AFP, alpha fetoprotein. including lung, esophageal, and gastric cancer. ${ }^{6-10}$ In 2006, $\mathrm{Su}$ et al first reported that suppression of CNTN1 expression abolished the ability of lung adenocarcinoma cells to invade and metastasize by activating RhoA, but not Cdc42 or Rac1. ${ }^{17,18}$ Furthermore, knockdown of CNTN1 resulted in increased survival in an animal model. Liu et al found that the expression of CNTN1 mRNA was significantly increased in tumor tissue compared with normal esophageal tissue. ${ }^{8}$ Moreover, protein levels for CNTN1 are upregulated in esophageal squamous cell carcinoma tissue and related to stage, lymph-node metastasis, and lymphatic invasion. Similarly, Wu et al also found that CNTN1 ablation notably suppressed the invasive potential of oral squamous cell carcinoma cell lines. ${ }^{5} \mathrm{Yu}$ et al showed that both mRNA and protein levels for CNTN1 were upregulated in gastric cancer, and the expression of CNTN1 significantly correlated with VEGF-C and VEGFR-3. ${ }^{7}$

In this study, we evaluated the expression and clinical significance of CNTN1 in HCC. The immunohistochemical analysis showed that CNTN1 protein levels were significantly higher in HCC tissues compared to adjacent nontumor tissues, and $\mathrm{HCC}$ tumors with $\mathrm{CNTN1}^{+}$expression were significantly related to tumor capsulae, tumor size, status of metastasis, and TNM stage when compared with HCC tumors with CNTN1 ${ }^{-}$ expression. Moreover, we also investigated the expression of CNTN1 at the transcription and protein level in paired HCC samples, and found it was higher in tumor tissues than in paracarcinomatous tissues. Therefore, our data suggested that high CNTN1 expression had an unfavorable outcome in $\mathrm{HCC}$, and CNTN1 may be a promising prognostic marker.

Although CNTN1 has been shown to promote cancer invasion and metastasis, the underlying mechanisms remain unclear. It is possible whether CNTN1 affects HCC progression and metastasis by activating AKT. Yan et al reported that CNTN1 can reduce E-cadherin expression in A549 lung cancer cells, and that activation of AKT plays a role in the

Table 3 Multivariate analysis of prognostic parameters associated with OS and DFS

\begin{tabular}{|c|c|c|c|c|c|c|}
\hline \multirow[t]{2}{*}{ Parameters } & \multicolumn{3}{|l|}{ os } & \multicolumn{3}{|l|}{ DFS } \\
\hline & HR & $95 \% \mathrm{Cl}$ & P-value & HR & $95 \% \mathrm{Cl}$ & $P$-value \\
\hline CNTNI (negative vs positive) & 2.383 & $1.262-4.503$ & 0.007 & 2.356 & $1.370-4.049$ & 0.002 \\
\hline Tumor size, $\mathrm{cm}(\leq 5$ vs $>5)$ & 3.006 & $1.438-6.286$ & 0.003 & 1.853 & $1.038-3.305$ & 0.037 \\
\hline Tumor capsulae (absent vs present) & 2.678 & $1.396-5.136$ & 0.003 & 2.616 & $1.487-4.60 \mathrm{I}$ & 0.001 \\
\hline Vascular invasion (no vs yes) & 2.391 & $1.291-4.427$ & 0.006 & 1.963 & I.117-3.449 & 0.019 \\
\hline Edmondson grade (I-II vs III-IV) & 1.533 & $0.825-2.847$ & 0.177 & 1.486 & $0.866-2.550$ & 0.150 \\
\hline AFP, ng/mL ( $\leq 20$ vs $>20)$ & 2.605 & $1.345-5.044$ & 0.005 & 1.758 & $1.007-3.067$ & 0.047 \\
\hline Metastasis status (present vs absent) & 1.97 & $1.093-3.55 \mathrm{I}$ & 0.024 & 1.623 & $0.912-2.890$ & 0.115 \\
\hline TNM stage (I-II vs III-IV) & 2.033 & $|| 38-3.63 \mid$. & 0.017 & 3.953 & $2.213-7.064$ & $<0.001$ \\
\hline
\end{tabular}

Abbreviations: OS, overall survival; DFS, disease-free survival; HR, hazard ratio; Cl, confidence interval; TNM, tumor, node, metastasis; AFP, alpha fetoprotein. 
downregulation of E-cadherin that is CNTN1-mediated. ${ }^{4}$ Existing evidence shows that abnormal activation of the PI3K-Akt-mTOR signaling pathway frequently occurs in HCC. ${ }^{19-21}$ Also, Zhou et al showed that this pathway is associated with poor prognosis in $\mathrm{HCC}$ patients. ${ }^{22}$ Furthermore, there is research to show that CNTN1 is a downstream effector of VEGF-C, which is a key regulator of angiogenesis and lymphangiogenesis. ${ }^{18}$ It is widely accepted that tumor angiogenesis is a key component in tumor metastasis. ${ }^{23}$ Liu et al found that VEGF-C can stimulate esophageal cancer cell growth, migration, and focus formation via regulating the expression of CNTN1. ${ }^{24}$ Therefore, CNTN1 may be involved in VEGF-Cmediated tumor angiogenesis in HCC. However, the possible correlation between the expression of CNTN1 and VEGF-C in HCC metastasis remains to be elucidated.

Existing studies have demonstrated the prognostic significance of CNTN1 expression in different malignancies. $\mathrm{Wu}$ et al reported that CNTN1 expression was significantly associated with OS and DFS of patients with oral squamous cell carcinoma. ${ }^{5}$ Similarly, Yu et al suggested that the detection of CNTN1 expression may be a useful indicator of poorer prognosis in gastric cancer. ${ }^{7}$ Using Kaplan-Meier analysis and the log-rank test, we revealed that $\mathrm{HCC}$ patients with $\mathrm{CNTN} 1^{+}$ tumors had a significantly shorter OS and DFS than those with $\mathrm{CNTN1}^{-}$tumors. Furthermore, using the Cox proportional hazard regression model, we identified CNTN1 as an independent prognostic factor for $\mathrm{HCC}$ patients after surgical resection. Consistent with the role of CNTN1 in the progression of human cancers, studies have shown that silencing CNTN1 expression prevents tumor-cell migration and invasion. ${ }^{17,25}$ The adverse prognostic effect of CNTN1 further suggests a tumor-promoting role for this gene in HCC. However, the underlying molecular mechanisms by which CNTN1 overexpression results in poor patient outcome are unclear and require further investigation.

A major limitation of this single-institute study was its relatively small sample size. In addition, there was potential selection bias in which selected individuals were not truly representative to take part in this retrospective study; this was due to such factors as admission-rate bias, detection-signal bias, and nonrespondent bias. Therefore, more prospective studies with larger cohorts of subjects are needed to support the present findings.

In conclusion, we have provided the first evidence that CNTN1 is overexpressed in HCC tissues, and that high expression of CNTN1 is associated with aggressive clinicopathological features. Notably, CNTN1 ${ }^{+}$expression is an independent predictor of poor OS and DFS in HCC patients receiving surgical resection. Our data suggest that $\mathrm{CNTN} 1$ may contribute to tumor metastasis and invasion in HCC. However, further investigations are required to reveal the biological relevance of increased expression of CNTN1 in HCC.

\section{Acknowledgments}

This research was supported by the National Natural Science Foundation of China (81172364) and the Natural Science Research project of Anhui Colleges and Universities (KJ2013A143).

\section{Disclosure}

The authors report no conflicts of interest in this work.

\section{References}

1. Jemal A, Bray F, Center MM, Ferlay J, Ward E, Forman D. Global cancer statistics. CA Cancer J Clin. 2011;61:69-90.

2. Blechacz B, Mishra L. Hepatocellular carcinoma biology. Recent Results Cancer Res. 2013;190:1-20.

3. Berglund EO, Ranscht B. Molecular cloning and in situ localization of the human contactin gene (CNTN1) on chromosome 12q11-q12. Genomics. 1994;21:571-582.

4. Yan J, Wong N, Hung C, Chen WX, Tang D. Contactin-1 reduces E-cadherin expression via activating AKT in lung cancer. PLoS One. 2013;8:e65463

5. Wu HM, Cao W, Ye D, Ren GX, Wu YN, Guo W. Contactin 1 (CNTN1) expression associates with regional lymph node metastasis and is a novel predictor of prognosis in patients with oral squamous cell carcinoma. Mol Med Rep. 2012;6:265-270.

6. Liu P, Chen S, Wu W, et al. Contactin-1 (CNTN-1) overexpression is correlated with advanced clinical stage and lymph node metastasis in oesophageal squamous cell carcinomas. Jpn J Clin Oncol. 2012;42: 612-618.

7. Yu JW, Wu SH, Lu RQ, et al. Expression and significances of contactin-1 in human gastric cancer. Gastroenterol Res Pract. 2013;2013:210205.

8. Liu YC, Zhao J, Hu CE, Gan J, Zhang WH, Huang GJ. Comprehensive analysis of vascular endothelial growth factor-C related factors in stomach cancer. Asian Pac J Cancer Prev. 2014;15:1925-1929.

9. Prag S, Lepekhin EA, Kolkova K, et al. NCAM regulates cell motility. J Cell Sci. 2002;115:283-292.

10. Shtutman M, Levina E, Ohouo P, Baig M, Roninson IB. Cell adhesion molecule L1 disrupts E-cadherin-containing adherens junctions and increases scattering and motility of MCF7 breast. Cancer Res. 2006;66: $11370-11380$

11. Edge SB, Byrd DR, Compton CC et al. The American Joint Committee on Cancer: the 7th edition of the AJCC cancer staging manual and the future of TNM[J]. Ann Surg Oncol. 2010;17:1471-1474.

12. Wang W, Li GY, Zhu JY et al. Overexpression of AGGF1 is correlated with angiogenesis and poor prognosis of hepatocellular carcinoma. Med Oncol. 2015;32(4):131.

13. Fujita N, Nagata S. Contactin 1 knockdown in the hindbrain induces abnormal development of the trigeminal sensory nerve in Xenopus embryos. Dev Genes Evol. 2007;217:709-713.

14. Mikami T, Yasunaga D, Kitagawa H. Contactin-1 is a functional receptor for neuroregulatory chondroitin sulfate-E. J Biol Chem. 2009; 284:4494-4499.

15. Bizzoca A, Virgintino D, Lorusso L, et al. Transgenic mice expressing F3/contactin from the TAG-1 promoter exhibit developmentally regulated changes in the differentiation of cerebellar neurons. Development. 2003;130:29-43.

16. Compton AG, Albrecht DE, Seto JT. Mutations in contactin-1, a neural adhesion and neuromuscular junction protein, cause a familial form of lethal congenital myopathy. Am J Hum Genet. 2008;83:714-724.

17. Su JL, Yang CY, Shih JY, et al. Knockdown of contactin-1 expression suppresses invasion and metastasis of lung adenocarcinoma. Cancer Res. 2006;66:2553-2561. 
18. Su JL, Yang PC, Shih JY, et al. The VEGF-C/Flt-4 axis promotes invasion and metastasis of cancer cells. Cancer Cell. 2006;9:209-223.

19. Zhou Q, Lui VW, Yeo W. Targeting the PI3K/Akt/mTOR pathway in hepatocellular carcinoma. Future Oncol. 2011;7:1149-1167.

20. Sahin F, Kannangai R, Adegbola O, Wang J, Su G, Torbenson M. $\mathrm{mTOR}$ and P70S6 kinase expression in primary liver neoplasms. Clin Cancer Res. 2004;10:8421-8425.

21. Villanueva A, Chiang DY, Newell P, et al. Pivotal role of mTOR signaling in hepatocellular carcinoma. Gastroenterology. 2008;135: 1972-1983.

22. Zhou LD, Huang Y, Li JD, Wang ZM. The mTOR pathway is associated with the poor prognosis of human hepatocellular carcinoma. Med Oncol. 2010;27:255-261.
23. Folkman J. Role of angiogenesis in tumor growth and metastasis. Semin Oncol. 2002;29:15-18.

24. Liu P, Zhou J, Zhu H, et al. VEGF-C promotes the development of esophageal cancer via regulating CNTN-1 expression. Cytokine. 2011; 55:8-17.

25. Chen H, Yu JW, Wu JG, Wang SL, Jiang BJ. Significances of contactin-1 expression in human gastric cancer and knockdown of contactin-1 expression inhibits invasion and metastasis of MKN45 gastric cancer cells. J Cancer Res Clin Oncol. 2015;141:2109-2120.

\section{Publish your work in this journal}

OncoTargets and Therapy is an international, peer-reviewed, open access journal focusing on the pathological basis of all cancers, potential targets for therapy and treatment protocols employed to improve the management of cancer patients. The journal also focuses on the impact of management programs and new therapeutic agents and protocols on

\section{Dovepress}

\footnotetext{
Submit your manuscript here: http://www.dovepress.com/oncotargets-and-therapy-journal
}

patient perspectives such as quality of life, adherence and satisfaction. The manuscript management system is completely online and includes a very quick and fair peer-review system, which is all easy to use. Visit http://www.dovepress.com/testimonials.php to read real quotes from published authors. 